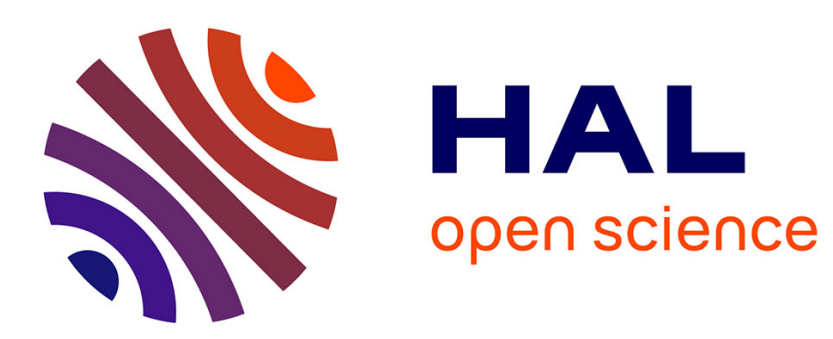

\title{
Thermomechanical behavior of PA6.6 composites subjected to low cycle fatigue
}

Adil Benaarbia, André Chrysochoos, Gilles Robert

\section{To cite this version:}

Adil Benaarbia, André Chrysochoos, Gilles Robert. Thermomechanical behavior of PA6.6 composites subjected to low cycle fatigue. Composites Part B: Engineering, 2015, 76, pp.52-64. 10.1016/j.compositesb.2015.02.011 . hal-01122243

\section{HAL Id: hal-01122243 \\ https://hal.science/hal-01122243}

Submitted on 3 Mar 2015

HAL is a multi-disciplinary open access archive for the deposit and dissemination of scientific research documents, whether they are published or not. The documents may come from teaching and research institutions in France or abroad, or from public or private research centers.
L'archive ouverte pluridisciplinaire HAL, est destinée au dépôt et à la diffusion de documents scientifiques de niveau recherche, publiés ou non, émanant des établissements d'enseignement et de recherche français ou étrangers, des laboratoires publics ou privés. 


\title{
Thermomechanical behavior of PA6.6 composites subjected to low cycle fatigue
}

\author{
Adil Benaarbia ${ }^{\mathrm{a}, \mathrm{b},{ }^{*}, \text { André Chrysochoos }}{ }^{\mathrm{a}}$, Gilles Robert ${ }^{\mathrm{b}}$ \\ ${ }^{a}$ University Montpellier 2, LMGC Laboratory, CNRS, Place Eugène Bataillon, 34095 Montpellier, France \\ b Solvay Engineering Plastics, Technyl Innovation Center-Simulation et Validation des Applications, Avenue Ramboz - BP64, 69192 Saint Fons, France
}

Keywords:

A. Polymer-matrix composites (PMCs)

B. Fatigue

B. Thermomechanical

D. Non-destructive testing

\begin{abstract}
A B S T R A C T
In this study, manifold experiments were conducted to investigate the thermomechanical behavior of short E-glass fiber-reinforced polyamide 6.6 composites subjected to low cycle fatigue loadings. Different hygrometric states, fiber configurations and loading rates were considered. Mechanical, thermal and energy responses of composite specimens were recorded using photomechanic techniques. The influence of water content, fiber orientation and loading rate on these thermomechanical responses was systematically analysed.

The mechanical findings indicated that the ratcheting phenomenon was more pronounced for humid composites reinforced with fibers oriented transversely and subjected to a low loading rate. Moreover, the order of magnitude in self-heating was greater for transversal fiber composites conditioned at high relative humidity and subjected to a $10 \mathrm{~Hz}$ loading rate. From a thermodynamic standpoint, we also noticed that high proportions of the mean stored energy rate were obtained at a high loading rate, with values exceeded $64 \%$. These values were noticeably altered by the water content and fiber angles, i.e. lower as the relative humidity increased and higher as the fiber angles increased.
\end{abstract}

\section{Introduction}

Short E-glass fiber-reinforced polyamides 6.6 (SGFR/PA6.6) are a class of thermoplastic engineering materials of growing commercial importance. The interest in these composites has increased substantially because of their ease of manufacturing and noteworthy thermomechanical properties. They can be processed using rapid fabrication techniques (e.g. injection molding) and are already being used successfully in several applications, notably in the automotive industry.

The fibers can adopt complex orientation patterns during injection molding. These patterns can affect the thermophysical properties of SGFR/PA6.6, which may show significant anisotropy due to the preferred orientation of the fibers. Here we intended to explore and highlight the dependence of the thermomechanical features of SGFR/PA6.6 on fiber configurations. Moreover, these features may not solely depend on the fiber orientation, but also on the water content [1]. For instance, the water content causes a

\footnotetext{
* Corresponding author. University Montpellier 2, LMGC laboratory, CNRS, Place Eugène Bataillon, 34095 Montpellier, France. Tel.: +33 467143432. E-mail address: abenaarb@univ-montp2.fr (A. Benaarbia).
}

reduction in the strength and modulus of SGFR/PA6.6 while increasing the ductility [2]. It also causes SGFR/PA6.6 to swell [3], and the amount of swelling strongly depends on the extent of moisture uptake.

Studies carried out to date have mainly been focused on nonlinear time-dependent [4] and fatigue damage [5] behaviors of injected molded 35-30\%wt short glass fiber-reinforced PA6.6 composites. Previous studies dealing with pure PA6.6 matrix behavior showed that the tensile strength was roughly twofold lower when comparing fully moisture saturated specimens and dry-as-molded specimens [6]. For cyclic loadings, it was found that self-heating was approximately tenfold lower for dry PA6.6 specimens than for humid ones, for the same stress and loading frequency. Besides, the form of the energy rate balance changed completely between dry-as-molded and humid PA6.6 specimens due to plasticizing effects. The objective of the present study was also to examine if such energy behavior could occur for SGFR/PA6.6 where, by definition, plasticization of the matrix could be expected to be substantial for high relative humidity levels. We also felt it was of prime interest to study how the internal moisture could affect the glass transition temperature. Glass transition is defined as a gradual thermally activated process that leads a polymer to change from glassy to rubbery state $[7,8]$. This glass transition 
temperature, which largely depends on the ambient temperature and relative humidity, has been explained by many theories as being related to the onset of movements in the macromolecular network of polymers [9].

The LCF behavior of SGFR/PA6.6 varies greatly compared to that of non-reinforced material. This is due to the high degree of heterogeneity and anisotropy induced by the presence of glass fibers. In quasi-isotropic materials such as pure PA6.6 matrix, full-field measurement analyses indicate that, at the very beginning of loading, a single dominant localization region appears with relatively small localized bands [10]. However, with fiber-reinforced composites, the localizations are often in several zones, diverted and directed along the fiber angles [11], thus indicating numerous possible failure onset zones. These failure zones can display matrix cracking, fiber failure and interfacial debonding [12]. They can also occur separately or interactively, thus complicating the study and prediction of the SGFR/PA6.6 behavior. As there are only few databases on SGFR/PA6.6 fatigue properties relative to those of metals, for instance, comprehensive investigations are still required in order to monitor and gain greater insight into the cyclic behavior of SGFR/PA6.6. In reinforced PA6.6 composites, the behavior is strongly dependent on the loading and environmental conditions (loading frequency, relative humidity, stress level, etc.), material properties and structural arrangement (fiber orientation angles, fraction mass of fibers, crystallinity rate of the polymer matrix, etc.). Some previous studies have focused on this behavior under tensile and cyclic loading conditions $[4,5,11,13-16]$.

The thermomechanical behavior of SGFR/PA6.6 is not yet as well understood as the mechanical behavior. Many experimental surveys based on energy balances are needed to improve constitutive material models, thus facilitating the use and application of such engineering materials. More precisely, assessments of the stored and dissipated energies could provide crucial information on the microstructural changes and the nature of their irreversibility. The most significant developments in the computation and interpretation of stored and dissipated energies are closely related to calorimetric procedures. The earliest published studies on this subject were focused on metallic materials. Farren and Taylor [17] and Taylor and Quinney [18] were among the first to build an apparatus to measure dissipated energy during the deformation of metallic materials subjected to quasi-static monotonous tensile tests. Williams [19] and Leach [20] reviewed calorimetric methods in detail and assessed calorimetry procedures and equipment applicable for heat energy measurement. Most investigations have focused on the Taylor-Quinney coefficient, which expresses the fraction of the anelastic deformation energy rate irreversibly converted into heat, i.e. dissipated. We underline the fact that these early studies were carried out with standard measurement devices involving thermocouples and microcalorimeters. In the early 1980s, with the introduction of infrared cameras, new experimental approaches to the energy analysis of material behavior were developed (see. e.g. Refs. [21-23]).

Indeed, drawing up energy balances may provide greater insight into the evolution of dissipative phenomena that cause temperature increases (or decreases) observed when materials are subjected to mechanical loadings. Many experimental, theoretical and numerical studies have still been focused on determining such energy balances [24-28]. Complete energy balances are determined by computing all energies involved during the deformation process. Generally, the stored energy is assessed according to the difference between the mechanical energy required for deformation of the material and the dissipated energy. The total deformation energy is usually determined from force-displacement data. This total energy includes the elastic and anelastic energy of the deformed specimen. The heat produced by the deformation is usually obtained from a heat balance associated with the deformation. Many interesting surveys on specific aspects of the stored energy can be found in the literature. Several research studies using calorimetric techniques have focused on determining changes in temperature increases during loadings [29,22,30-32]. However, for repetitive loading, few previous investigations have measured stored energy for polymeric composite materials. To our knowledge, no studies have been published concerning the establishment of energy balances for SGFR/PA6.6 under hygrometric conditions and through many thousands of fatigue cycles. Most investigations have generally been concerned with the thermomechanical properties in tensile mode, and were undertaken without any energy considerations. This could be explained by difficulties and complexities due to the long time required for post-processing of the experimental data.

The major objectives of this research work were: i) thermomechanical characterization of fatigue mechanisms involved during deformation of SGFR/PA6.6 and, in particular, identification of the energy content of cyclic hysteresis loops, ii) quantification of internal moisture and fiber orientation effects on the thermomechanical responses of the studied engineering composites.

In this paper, the preparation of SGFR/PA6.6 specimens is first briefly described. The experimental tools and methods used for conducting experiments are then presented. The mechanical and thermal responses under different hygrometric, fiber states and loading rates are then shown and examined. Complete energy rate balances are then analyzed as well as the contribution of the mean stored energy rate per cycle. Experimental findings obtained with the different testing conditions and materials are compared. Several conclusions, drawn from the findings, are finally put forward, along with some proposals regarding future investigations.

\section{Experimental procedure}

\subsection{Specimen preparation and loading}

Injection-molded rectangular SGFR/PA6.6 plates were used. The SGFR/PA6.6 plates were provided by Solvay Engineering Plastics and are commercially available under the trade name A218V30. The E-glass fibers ( $10 \mu \mathrm{m}$ average diameter, $250 \mu \mathrm{m}$ average length) were surface treated with a special chemical coating to greatly enhance the adhesive links between composite constituents (short fibers and PA6.6 matrix). The weight fraction of short glass fibers embedded in the polyamide 6.6 matrix is in the range of $30 \pm 1 \mathrm{wt} \%$. Three different hygrometric states were considered: viz. RH0 (conditioned in a vacuum oven at $80{ }^{\circ} \mathrm{C}$ for $15 \mathrm{~h}$ ), RH50 (prepared according to the ISO1110 standard by conditioning inside a weathering chamber at $70^{\circ} \mathrm{C}$ and $\mathrm{RH}=62 \%$ for 9 days, then at $23^{\circ} \mathrm{C}$ and $\mathrm{RH}=50 \%$ for 15 days) and $\mathrm{RH} 80$ (first conditioned at $70^{\circ} \mathrm{C}$ and $\mathrm{RH}=80 \%$, then at $30^{\circ} \mathrm{C}$ and $\mathrm{RH}=80 \%$ until mass stability) [33]. For PA6.6 matrix, the range of glass transition temperature values associated with previous hygrometric states are given in Table 1. Tensile specimens of $100 \mathrm{~mm}$-in-overall-length by $20 \mathrm{~mm}$-in-gagewidth and $3.14 \mathrm{~mm}$-in-thickness were cut from these SGFR/PA6.6 plates as required (suitable size and shape for the clamping jaws of the loading machine) using a high speed router. During cutting, three different fiber configurations, with respect to the loading direction, were designated as $\mathrm{MGF0}^{\circ}, \mathrm{MGF}^{\circ} 5^{\circ}$ and $\mathrm{MGF90} 0^{\circ}$ for the

Table 1

Relative humidity $(\mathrm{RH})$ versus the glass transition temperature $\left(T_{g}\right)$ of the polyamide 6.6 matrix (courtesy of Solvay Engineering Plastics).

\begin{tabular}{lllr}
\hline Relative humidity $(\%)$ & 0 & 50 & 80 \\
Glass transition temperature $\left({ }^{\circ} \mathrm{C}\right)$ & $65-70$ & $18-26$ & 0 \\
\hline
\end{tabular}


mean fiber orientation angles $0^{\circ}, 45^{\circ}$ and $90^{\circ}$, respectively. The final specimen geometries and mean fiber orientations are shown in Fig. 1. These SGFR/PA6.6 plates exhibit anisotropic behavior due to the skin-shell-transition-core microstructures [33]. However, it is considered that most fibers in the specimens are aligned in the mold fill axis. This consideration was taken into account during this study.

Tensile-tensile uniaxial fatigue tests in stress control and sinusoidal waveform (see Fig. 2) at 1 and $10 \mathrm{~Hz}$ were carried out on composite specimens at non-zero mean stress and room temperature $\left(23^{\circ} \mathrm{C}\right)$. The load ratio was set at 0.1 while the number of cycles was $10^{4}$. At the beginning of each test, the load signal was set at zero for $10 \mathrm{~s}$ to calculate the stabilized thermal image. Its displacement rate was then controlled with a constant cross-head velocity of $1 \mathrm{~mm} \mathrm{~s}^{-1}$, with stress maintained at $\sigma_{\min }$ for $3 \mathrm{~s}$ and tensile-tensile loading between $\sigma_{\min }$ and $\sigma_{\max }$.

\subsection{Apparatus and test methods}

The thermal measurements were conducted using a Flir titanium infrared camera. This thermal imaging system included a Stirling cycle cooled indium antimonide (InSb) detector with a focal plane array of $512 \times 640$ elements, coded on 14 bits This InSb detector is sensitive to infrared radiation in the $3-5 \mu \mathrm{m}$ wavelength range (middle waves). The thermal sensitivity of the camera was above $25 \mathrm{mK}$. The camera was placed perpendicular to the gauge section of the samples in order to avoid geometrical and metrological errors (Lambert's conditions). The sample to camera distance was maintained at $0.8 \mathrm{~m}$ in all loading cases. Several window sizes were available and we decided to operate with a $160 \times 128$ pixel window size (a quarter of the available full window size) and $29 \mu \mathrm{m}$ pixel size. This small window size enabled us to acquire several images, up to 85,000 images for a data storage capacity of 20 Go per test. The frame rate of the camera was set at tenfold the loading frequency to obtain enough sampled data in order to improve the signal-to-noise ratio using local least-squares approximation. The frame rate was thus set at $10 \mathrm{~Hz}$ for tests performed at a $1 \mathrm{~Hz}$ loading rate. Moreover, we decided to operate with a $900 \mu$ s integration time (electronic charge accumulation time) in order to optimize the measurement accuracy according to the observed temperature range. Generally, a longer time reduces the temporal noise (mainly of thermal origin), but this can lead to detector element saturation and reduce the maximum acquisition rate. Thermal images were recorded continuously for whole fatigue cycles and were stored in a computer hard drive. The control computer was equipped with ALTAIR software, which enabled us to visualize and analyze the thermal images captured by the IR camera. During the experiments, several experimental precautions were taken to overcome some difficulties inherent to the thermal measurements. As the heat flux density transferred to the infrared sensor included noise components due to the reflected incident energy from the surroundings, the IR measurements were therefore done indoors and the experimental tools were screened and

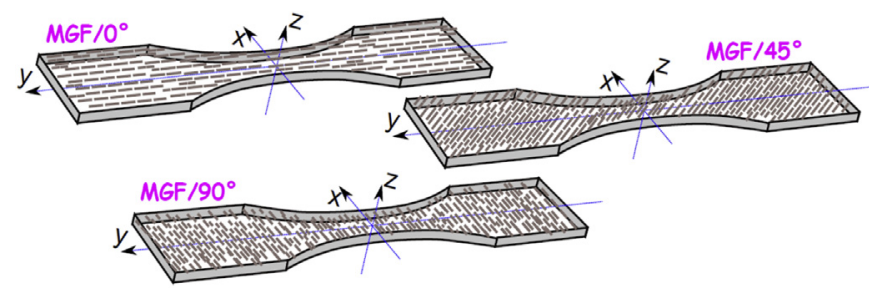

Fig. 1. Sketch of composite sample configurations at different fiber orientations.

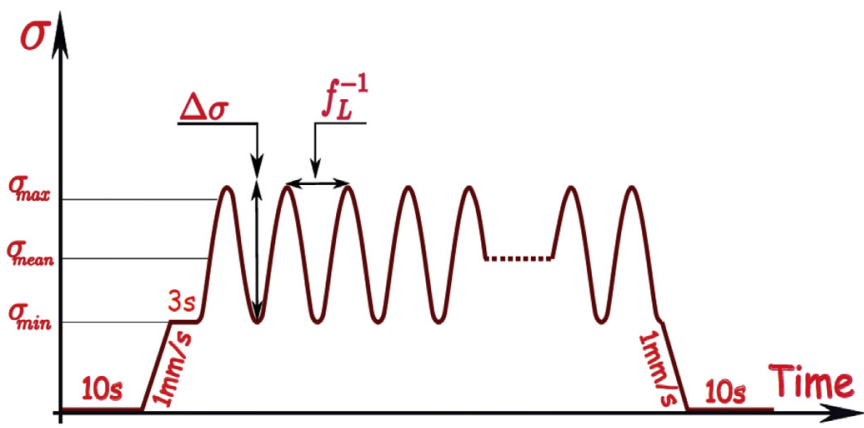

Fig. 2. Diagram of the mechanical loading used in the experiments.

isolated far from the radiation sources of the surroundings. Some parts of the loading machine were wrapped with paper in order to avoid infrared parasitic reflections onto the specimen. The camera was also turned on for $4 \mathrm{~h}$ before starting the experiments in order to reach thermal equilibrium. The temperature was quantitatively measured after improving the surface emissivity. The tested specimens were coated with matt black paint, and were then assumed to be perfect black bodies with an emissivity value close to 1 . Finally, a dummy specimen was placed close to the tested one to monitor possible temperature changes in the testing area.

An appropriate calibration protocol was also conducted to determine the temperature recorded by the IR camera. This procedure allowed conversion of the thermal radiation digitized by the infrared camera into temperature using pixel calibration functions [34]. This pixel protocol was based on a polynomial fitting of the digital levels $\mathrm{DL}_{(\mathrm{i} . \mathrm{j})}$ delivered by each individual detector element $(\mathrm{i}, \mathrm{j})$ using a black body with a uniform high emissivity coating, maintained at cold and hot temperatures $T_{(\mathrm{i}, \mathrm{j})}$. The measurement accuracy could thus be assessed for each pixel individually in the resulting image.

$T_{(\mathrm{i}, \mathrm{j})}=\sum_{m=0}^{d_{f}} \chi_{(i, j)_{m}} \mathrm{DL}_{(\mathrm{i}, \mathrm{j})}^{m}$

where $d_{f}$ denotes the degree of the polynomial fitting function and $\chi_{(i, j)_{m}}$ are coefficients of the calibration law for the element $(\mathbf{i}, \mathbf{j})$. These coefficients were derived from least-squares fitting approximations.

Finally, a local least-square fitting method using an optimized approximation function set was developed to reduce the noise effect [35].

\section{Experimental results}

\subsection{Cyclic stress-strain hysteresis loops}

Several properties regarding the cyclic behavior of materials can be extracted by plotting the hysteresis loops under stress vs strain curves. Figs. 3 and 4 show the mechanical responses of short-glass fiber-reinforced PA6.6 specimens subjected to uniaxial tensile-tensile tests, plotted at various fatigue cycles ranging from 10 to 8500 cycles. Different hygrometric states $(\mathrm{RH}=0,50$ and 90) and fiber configurations $\left(0^{\circ}, 45^{\circ}\right.$ and $\left.90^{\circ}\right)$ were considered in order to study the effect of both the water content and fiber angle change on the mechanical responses of the composites under investigation.

Generally speaking, an important characteristic that all composites had in common was the change in the shape and the drift of the hysteresis loops. Figs. 3 and 4 show that the stress-strain curves were never completely stabilized, and their size and shape changed 

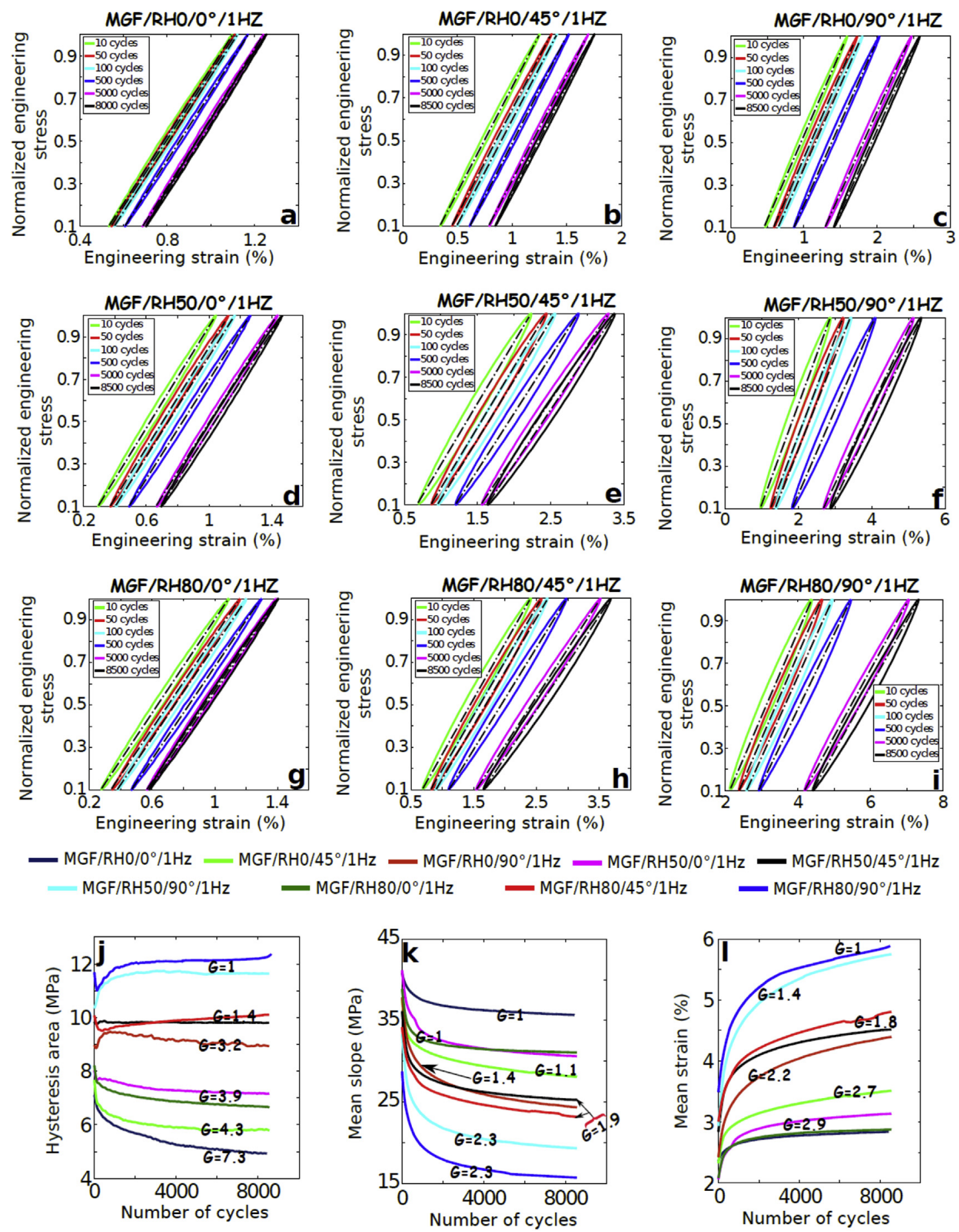

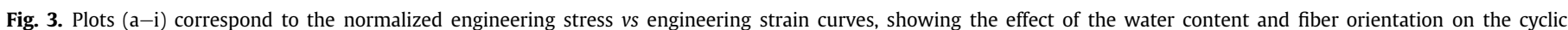

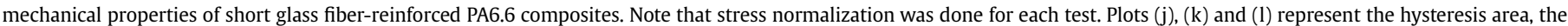
mean slope and mean strain per cycle as a function of the number of cycles. The loading frequency was $1 \mathrm{~Hz}$.

with increasing cycle number. Progressive mean strain per cycle accumulation took place due to the drift in the hysteresis loops. The mechanical behavior exhibited significant cyclic ratcheting with no stabilized state reached. The cyclic ratcheting trend altered noticeably with the hygrometric states and fiber configurations as can be noted in all of the selected sub-figures. This trend (drift of the hysteresis loops) was more significant for humid composites reinforced with fibers oriented at $45^{\circ}$ and $/$ or $90^{\circ}$ with respect to the tensile axis (see. e.g. Figs. 3 and 4, plots g, h and i).).
To characterize the mechanical response, we considered the following parameters associated with the hysteresis loop: the hysteresis area, the mean slope of the loop and the mean strain per cycle. These three parameters represent a quantitative measure of the cyclic mechanical responses. The time courses of these parameters are closely analyzed hereafter. They are schematically shown in Fig. 5. Figs. 3 and 4 (plots j, k and l) give the time courses associated with these three mechanical parameters as a function of the number of cycles for the different studied fiber configurations 

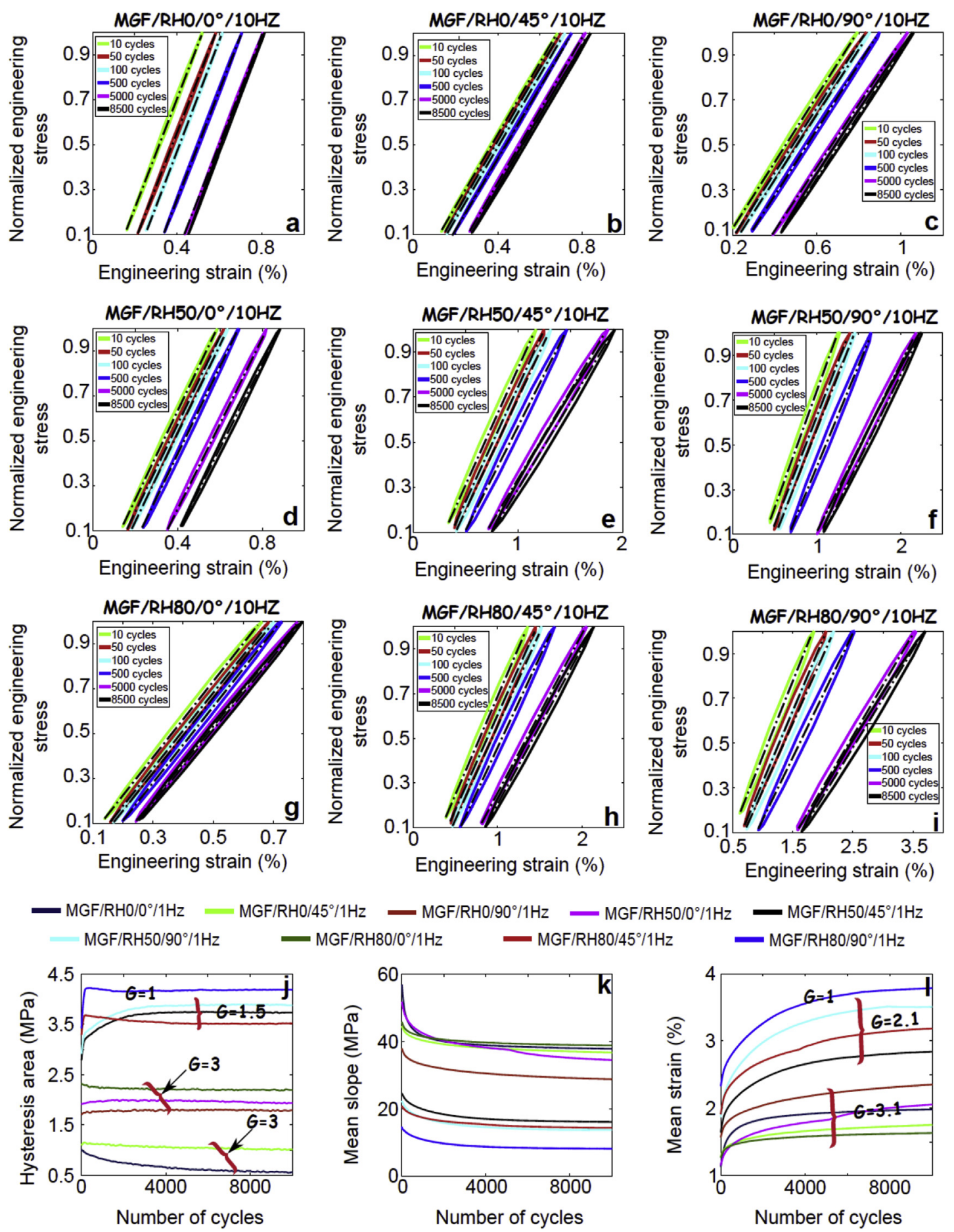

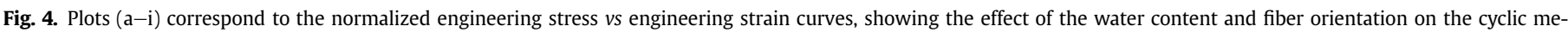

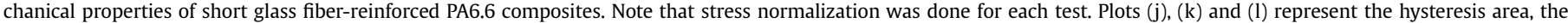
mean slope and mean strain per cycle as a function of the number of cycles. The loading frequency was $10 \mathrm{~Hz}$.

and hygrometric states. Note that different gains (scaling factors) were applied to the mechanical data to distinctly plot the variation patterns of these parameters on the same figure, thus facilitating their comparison. These gains (denoted $G$ ) are directly indicated on each curve.

\subsubsection{Hysteresis area}

To compare the amounts of deformation energy corresponding to the area of the hysteresis loops, hysteresis areas were calculated and plotted for the various dry and humid composites according to the number of cycles (see. Figs. 3 and 4, plot j). From the results, there was clearly a significant change in hysteresis area values when the fiber angle was altered. It is also inferred that the order of magnitude in values of the hysteresis areas was much higher for low loading frequency than for high loading frequency. At the end of loading, this order of magnitude ranged from $0.63 \mathrm{MPa}$ to $12 \mathrm{MPa}$ when the composites were subjected to $1 \mathrm{~Hz}$ loading frequency, and from 0.16 MPa to $4.5 \mathrm{MPa}$ under $10 \mathrm{~Hz}$ loading frequency. 


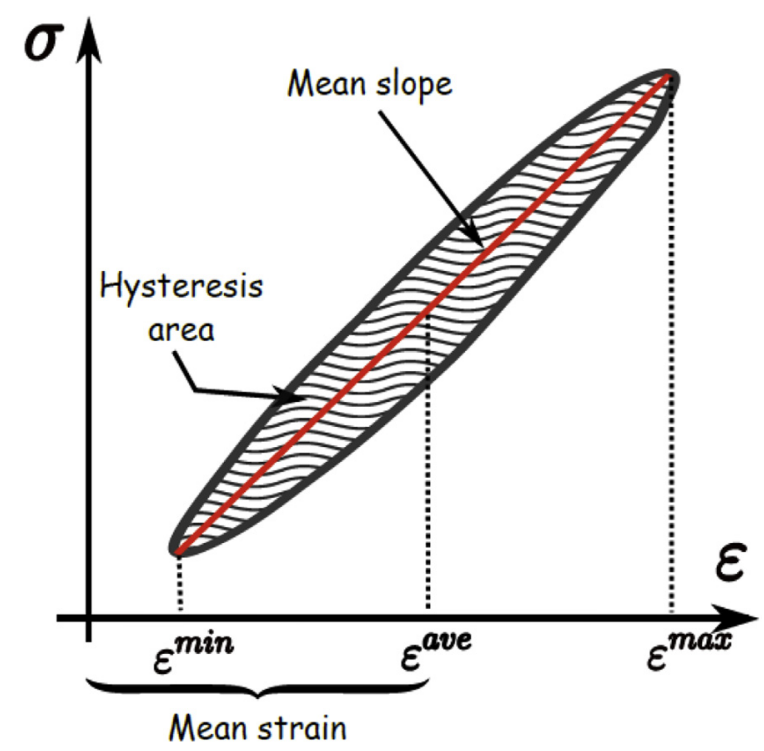

Fig. 5. Graphical representation of the hysteresis area, mean slope and mean strain per cycle.

Besides, loops associated with longitudinal fiber composites were much thinner compared to those in $45^{\circ}$ and $90^{\circ}$ fiber composites. We also noted that the hysteresis loop area values increased with increasing relative humidity. In other words, these hysteresis areas were larger for humid specimens (e.g. RH50 and RH80) than for dry-as-molded specimens. Moreover, the hysteresis loop area values decreased in the case of $\mathrm{MGF} / 0^{\circ}$ with an increasing number of cycles. However, non-monotone variations were observed in the case of $\mathrm{MGF} / 90^{\circ}$, where the hysteresis area values decreased initially at the very beginning of loading, and increased slightly for the rest of the cyclic loading period.

Note that it is still commonly acknowledged in the literature that the deformation energy loss during a mechanical cycle is due to material dissipation. The hysteresis area assessment is then used to estimate the dissipated energy. However, from a thermodynamic standpoint, it has been highlighted that, although intrinsic dissipation naturally contributes to the existence of a hysteresis loop, other phenomena may also modify the size of its area. It was recently underlined that the hysteresis area may not only be induced by intrinsic dissipation but also by internal energy variations due to microstructural transformations and/or strong thermomechanical coupling effects [36]. For pure polyamide 6.6, it has been shown that hysteresis loop areas were essentially induced by energy dissipation and storage (with the thermomechanical coupling sources per cycle being negligible) [6]. The energy analysis of SGFR/PA6.6 will be strengthened by experimental results and discussed in Subsec. 3.3.

\subsubsection{Mean strain}

In order to check whether the material would exhibit a marked ratcheting effect or not, the mean strain values per cycle were deduced from the experimental data (by integrating the strain maps over each cycle) and plotted in Figs. 3 and 4, plot l. These figures illustrate the time courses of the mean strain as a function of the number of cycles. This parameter exhibited a sharp increase at the very beginning of loading, and this increase became less marked as the number of cycles increased. Moreover, it is clear that this mean strain time course was strongly dependent on the fiber configuration and relative humidity change. When the relative humidity was maintained at a steady level, fiber orientations, as can be shown in Figs. 3 and 4 plot i, had a great effect on the mean strain intensities. The mean strain values increased markedly when changing the fiber angle from longitudinal to transverse direction. Note that the cyclic mean strain values associated with $\mathrm{MGF} / \mathrm{RH} 80 / 0^{\circ}$ were 6 -fold lower than those of $\mathrm{MGF} / \mathrm{RH} 80 / 90^{\circ}$. For $\mathrm{MGF} / \mathrm{RH} 80 / 0^{\circ}$, the cyclic mean strain had the lowest value of $0.86 \%$ compared with that of $\mathrm{MGF} / \mathrm{RH} 80 / 90^{\circ}$, which was roughly $6 \%$. Besides, when the relative humidity increased, the mean strain values increased correspondingly. For instance, the mean strain values were approximately $1.2 \%$ for $\mathrm{MGF} / \mathrm{RH} 0 / 45^{\circ}$, but they were $2.6 \%$ for $\mathrm{MGF} / \mathrm{RH} 80 / 45^{\circ}$. At high $\mathrm{RH}$ levels, a remarkable ratcheting occurred and increased progressively throughout the cycling, and no clear saturation was reached. For example, the cyclic mean strain in $\mathrm{MGF} / \mathrm{RH} 80 / 90^{\circ}$ was about threefold greater than that of $\mathrm{MGF} / \mathrm{RHO} / 90^{\circ}$. This relative humidity dependence was quite similar to that previously observed in the PA6.6 matrix behavior [6].

\subsubsection{Mean slope}

The mean hysteresis slope is defined as the slope that connects the 'extreme' points (in terms of stress range) of the hysteresis loops together (see. Fig. 5). The black dashed line indicated in all the loops of Figs. 3 and 4 shows this parameter symbolically. This fatigue parameter was thoroughly analyzed by tracking its changes throughout the cyclic loading test. The decrease in the mean slope up to 8500 cycles could be divided into two stages, as shown in Figs. 3 and 4, plot k. The first one was characterized by a steep reduction or decrease during the first few cycles (around one thousand), whereas the second stage indicated low degradation without reaching a real stable state, similarly to the observations extracted from the PA6.6 matrix mechanical behavior [10]. Note also that this decrease grew considerably with increasing relative humidity and/or fiber orientation. This decrease was more pronounced for high $\mathrm{RH}$ and transverse fiber orientations. Up to 8000 cycles, the loss in the mean slope was about $3 \mathrm{MPa}$ for $\mathrm{MGF} / \mathrm{RHO} / 0^{\circ}$ and $12.5 \mathrm{MPa}$ for $\mathrm{MGF} / \mathrm{RH} 80 / 90^{\circ}$. These results implied that increasing relative humidity and fiber angles (in the sense that fibers change from the longitudinal to transverse directions) led to a decrease in the mean slope and the fatigue life could eventually decrease as a result. These observations applied for all the varieties of PA6.6 composites investigated in this study.

Besides, the anisotropic mechanical elasticity observed in the composite materials at a fixed RH could be explained by the fiber orientations affecting the mechanical responses. When fibers were oriented at $0^{\circ}$ with respect to the loading axis, the maximum load was mostly taken by the reinforcing fibers and the material showed high strength and low ductility. Usually, the polymer matrix is much weaker in strength than reinforcing fibers. When fibers were oriented at $45^{\circ}$ with respect to the loading axis, this strength was reduced and the ductility started to grow due to local shear stresses within the matrix. When these local shear stresses exceeded the shear strength of the polymer matrix, they started dominating the composite behavior. Such fiber direction sensitivity was also observed through heterogeneous dissipative maps obtained by the IR procedure [11].

\subsection{Cyclic thermal responses}

In the following, mean temperature variations averaged over the sample gauge part of the composite materials are first outlined. These thermal responses were plotted as a function of the number of images for 1 and $10 \mathrm{~Hz}$ loading frequency in Figs. 6 and 7. For clarity, composite nominations are directly indicated on each subfigure. One immediate observation is that all thermal responses increased markedly at the very beginning of loading to reach quasistabilized values (at least for $1 \mathrm{~Hz}$ fatigue tests), as summarized in 

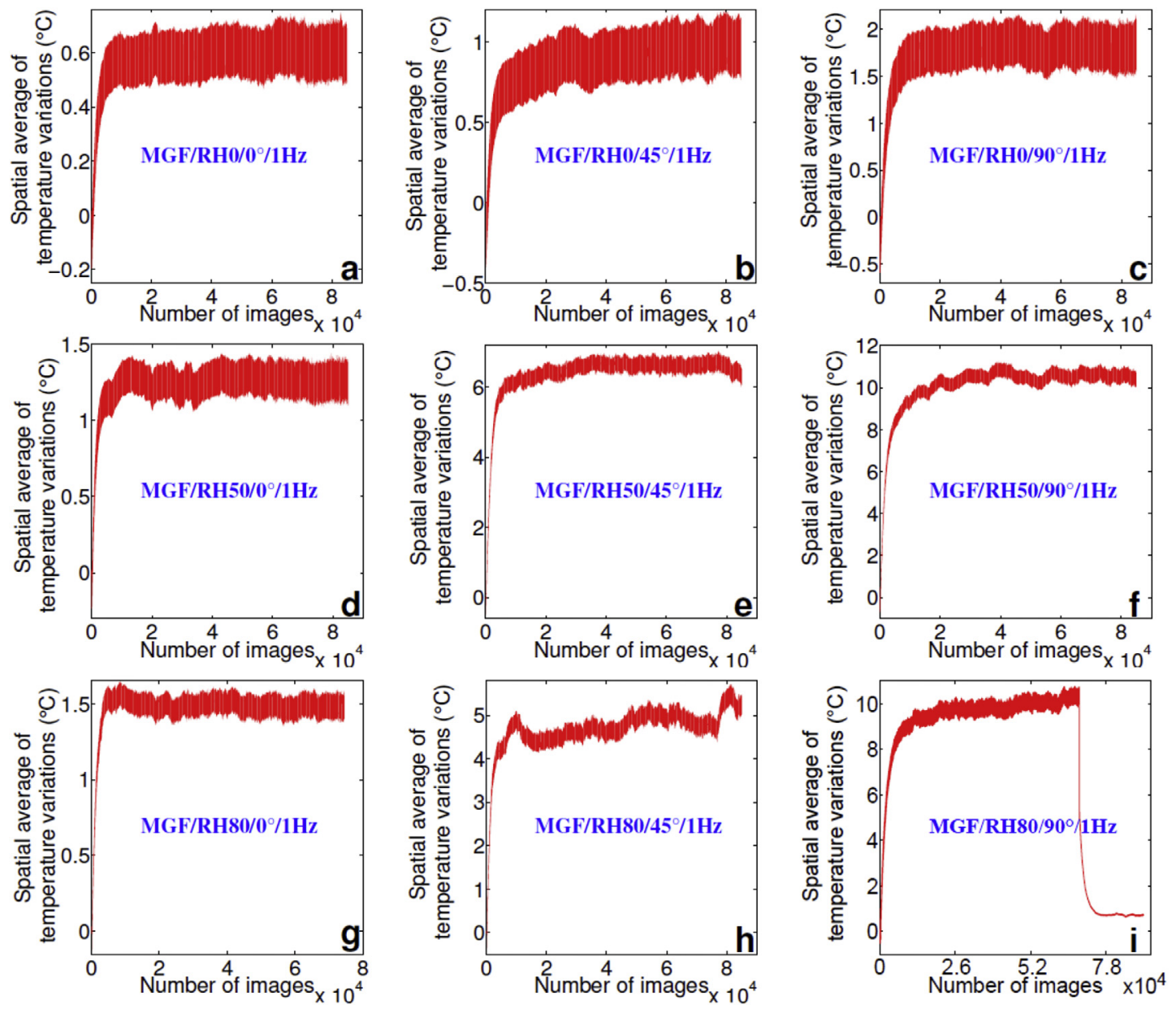

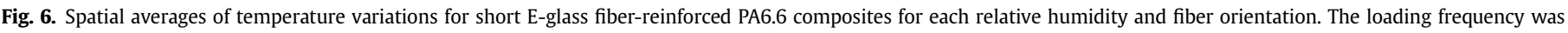
$1 \mathrm{~Hz}$.

Table 2. The results obtained when the number of cycles was further increased showed that these quasi-stabilized self-heating values reached by composites were obviously relative humidity and fiber orientation dependent. This noticeable self-heating should certainly be closer to the time course of the previous fatigue parameters characterizing the hysteresis loops. The temperature variations initially indicated a steep rise due to an increase in anelastic strain (the dissipative effect was activated). Then these temperature variations started to display a steady state region characterized by thermal stabilization throughout the $1 \mathrm{~Hz}$ fatigue test. From a calorimetric standpoint, this thermal steady state could be associated with an equilibrium between the dissipation intensity and thermal losses. We however stress that the stabilization in the mean temperature variations per cycle does not imply cyclic stabilization of the thermomechanical state. Note that this cyclic stabilization could occur if and only if all the hysteresis area is dissipated (no stored energy variations over the cycles). Moreover, it should be mentioned that the trends of all thermal curves obtained at $10 \mathrm{~Hz}$ loading frequency (see. Fig. 7) did not indicate any stable state as was observed at $1 \mathrm{~Hz}$ loading frequency (see. Fig. 6). As noted in all the selected experiments, the self-heating increased when the fiber angles changed from longitudinal to $45^{\circ}$ and $90^{\circ}$ directions. The same observation can be deduced from the effect of relative humidity. Although this relative humidity effect was less pronounced for longitudinal fiber composites, it appeared to be more significant for fiber-reinforced composites orientated at $45^{\circ}$ and $90^{\circ}$ (see. Table 2 ).
These results suggest that increasing the relative humidity and fiber angles leads to a marked increase in mean temperature variations. These results are also of crucial importance when thinking to the thermal sensitivity of composites behavior. For high hygrometric conditions and low loading frequencies, the material temperature became greater than the glass transition temperature. We then observed the inversion of the thermoelastic effect. This important point will no longer be discussed here as it has already been addressed for pure PA6.6 in Ref. [6]. Cyclic tests cannot be considered as isothermal mechanical tests from a modeling standpoint. When the temperature becomes greater than the glass transition temperature, a rubber behavior has to be considered for the matrix.

\subsection{Energy balances}

Energy storage reflects internal energy changes induced by anelastic transformations. An essential feature of this stored energy is that it remains in the deformed material, at least temporarily, until possible unloading or restoration processes. Generally, the stored energy amounts are computed as the difference between the deformation energy spent during the material transformation and the dissipated energy. In the case of standard quasi-static tests, the overall deformation energy $\mathcal{W}_{\text {def }}$ is determined, via the energy balance, from force-displacement data (or from stress-strain data for local analyses in the case of homogeneous tests). This deformation energy can be split into elastic $\mathcal{W}_{e}$ and anelastic $\mathcal{W}_{a n}$ 

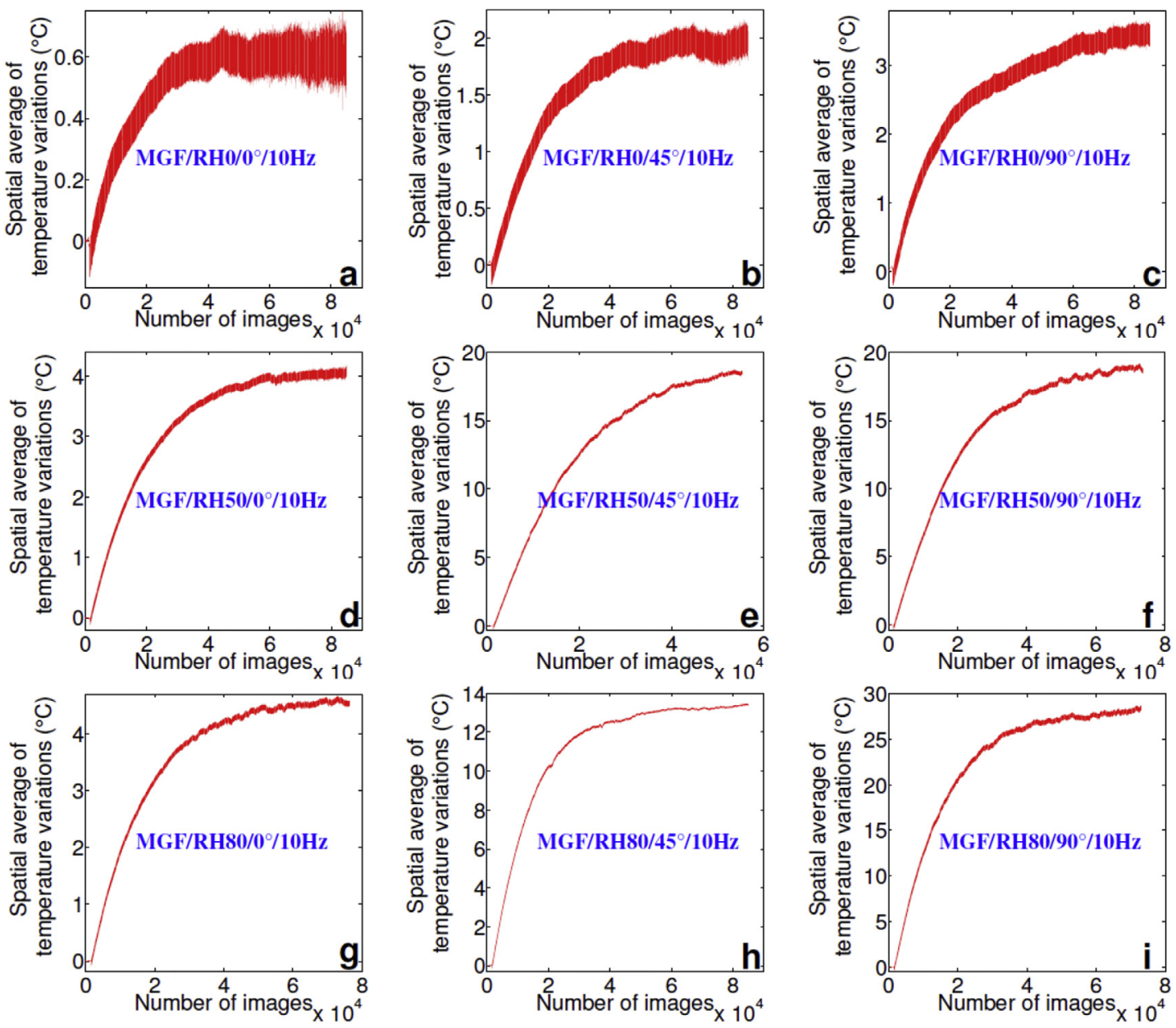

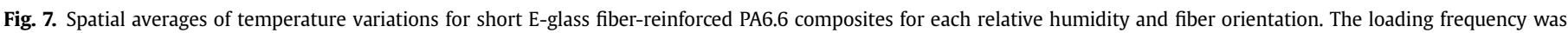
$10 \mathrm{~Hz}$.

energies, where $\mathcal{W}_{a n}$ is both stored and dissipated. In this context, the stored energy rate $\mathcal{W}_{s}^{\prime}$ reads [36]:

$\mathcal{W}_{s}^{\prime}=\mathcal{W}_{\text {def }}^{\prime}-\mathcal{W}_{e}^{\prime}-\mathcal{D}_{1}$

The term $\mathcal{D}_{1}$ stands for the intrinsic dissipation and characterizes the nature and intensity of material irreversibility accompanying the deformation process, whereas $\mathcal{W}_{s}^{\prime}$ translates the material microstructural changes (e.g. internal energy variation). Note that the non-standard notation (.)' specifies that (.) is path-dependent. For instance $\mathcal{W}_{s}^{\prime}$ represents the stored energy rate and means that this energy rate is not a state function.

According to this energy rate balance equation (2), a correct estimate of $\mathcal{W}_{\text {def }}^{\prime}, \mathcal{D}_{1}, \mathcal{W}_{e}^{\prime}$ leads to indirect assessment of $\mathcal{W}_{s}^{\prime}$. Only the assessment over each complete cycle of the above volume energy rates will be considered in the following. The mean elastic energy per cycle thus remains close to zero. Consequently, the mean deformation energy rate is approximately equal to the anelastic energy rate per unit volume and per cycle $\left(\tilde{\mathcal{W}}_{\text {def }}^{\prime}\right)^{i} \approx\left(\tilde{\mathcal{W}}_{a n}^{\prime}\right)^{i}(i$ representing the considered cycle number). The key issue here not only concerns computing the stored energy rate per unit volume and per cycle but also evaluating its contribution in the global energy balance. We thus defined the stored energy rate ratio, which is expressed by $\left(\tilde{\beta}_{s}\right)^{i}=\left(\tilde{\mathcal{W}}_{s}^{\prime}\right)^{i} /\left(\tilde{\mathcal{W}}_{\text {def }}^{\prime}\right)^{i}$. The values of this ratio are computed at the beginning and end of each cyclic test.

In the following, the mean deformation energy rate and dissipated energy as well as the stored energy, averaged over each complete cycle, were computed and plotted as a function of the mean strain in Figs. 8 and 9. All energy rates were assessed by post-processing of the experimental data. The mean dissipation energy rate averaged over a cycle $\tilde{\mathcal{D}}_{1}$ was calculated via the zerodimensional approach of the heat diffusion equation [37] as follows:

Table 2

Quasi-stabilized self-heating values associated with the investigated materials.

\begin{tabular}{|c|c|c|c|c|c|c|c|c|c|c|c|c|}
\hline \multirow[b]{2}{*}{ RH } & \multicolumn{3}{|c|}{ PA6.6/1 Hz } & \multicolumn{3}{|c|}{$\mathrm{MGF} / 0^{\circ} / 1 \mathrm{~Hz}$} & \multicolumn{3}{|c|}{$\mathrm{MGF} / 45^{\circ} / 1 \mathrm{~Hz}$} & \multicolumn{3}{|c|}{$\mathrm{MGF} / 90^{\circ} / 1 \mathrm{~Hz}$} \\
\hline & RHO & RH50 & RH80 & RHO & RH50 & RH80 & RHO & RH50 & RH80 & RHO & RH50 & RH80 \\
\hline \multirow[t]{2}{*}{$\theta_{s t b}\left({ }^{\circ} \mathrm{C}\right)$} & 2.5 & 16 & 30 & 0.6 & 1.2 & 1.5 & 0.9 & 6.4 & 4.5 & 1.8 & 10 & 10 \\
\hline & \multicolumn{3}{|c|}{ PA6.6/10 Hz } & \multicolumn{3}{|c|}{$\mathrm{MGF} / 0^{\circ} / 10 \mathrm{~Hz}$} & \multicolumn{3}{|c|}{$\mathrm{MGF} / 45^{\circ} / 10 \mathrm{~Hz}$} & \multicolumn{3}{|c|}{$\mathrm{MGF} / 90^{\circ} / 10 \mathrm{~Hz}$} \\
\hline RH & RHO & RH50 & RH80 & RHO & RH50 & RH80 & RHO & RH50 & RH80 & RHO & RH50 & RH80 \\
\hline$\theta_{\text {stb }}\left({ }^{\circ} \mathrm{C}\right)$ & 0.8 & 33 & 34 & 0.6 & 4 & 4.5 & 1.8 & 17 & 13.4 & 3.2 & 17 & 27 \\
\hline
\end{tabular}



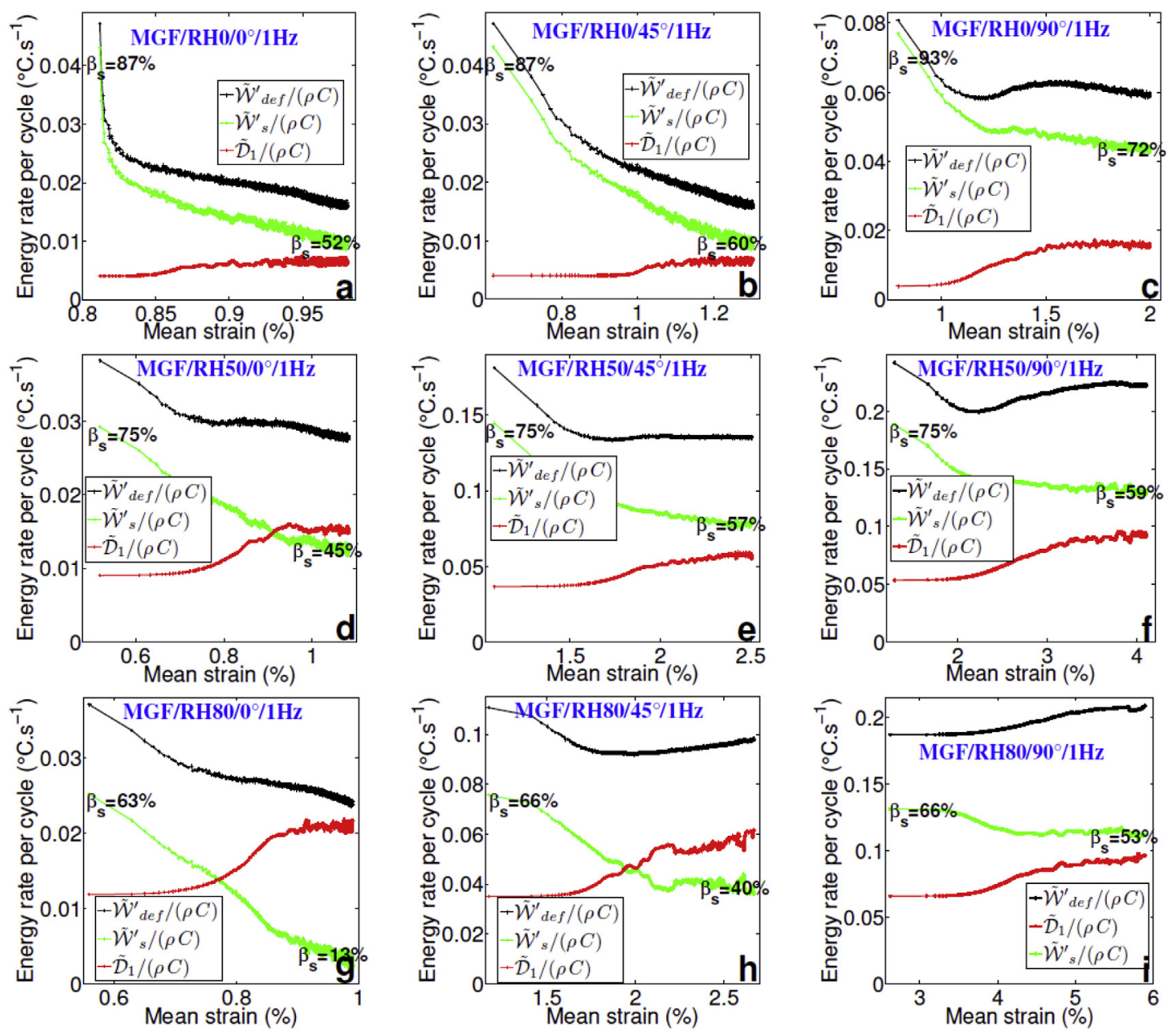

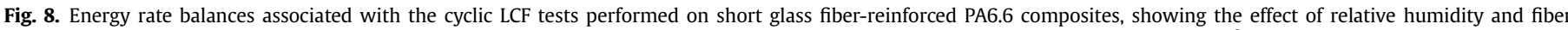
orientation. The load ratio was $R_{\sigma}=0.1$. The geometrical ratio was $r=0.56$ and the volume of the observed gauge area was $v_{g}=82 \mathrm{~mm}{ }^{3}$. The loading frequency was $1 \mathrm{~Hz}$.

$$
\left.\tilde{\mathcal{D}}_{1}=f_{L} \int_{(i-1) f_{L}^{-1}}^{i f_{L}^{-1}}\langle\dot{\theta}\rangle+\frac{\langle\theta\rangle}{\tau_{\text {th }}^{\text {Od }}}\right) d \tau
$$

where $\langle\theta\rangle=T-T_{0}$ is the temperature variation averaged over the volume element under investigation, $f_{L}$ denotes the loading frequency and $\tau_{\text {th }}^{\text {d }}$ a time constant characterizing overall heat exchanges between this volume element and the surroundings. This dissipative term $\tilde{\mathcal{D}}_{1}$ was determined by estimating the derivative operator $\dot{\theta}$ using IR thermal data.

The deformation energy represented by the area enclosed by hysteresis loops represents the ability of the material to cyclically deform. Its rate per cycle was estimated using the expression below:

$\widetilde{\mathcal{W}}_{d e f}^{\prime}=\frac{f_{L} r}{v_{g}} \int_{(i-1) f_{L}^{-1}}^{i f_{L}^{-1}} F d l_{s}$

where $F, l_{s}$ and $v_{g}$ are respectively the applied force, the global specimen elongation and the volume of the gauge area. $r$ represents a geometrical ratio. This ratio connects the global mechanical response to the local one with respect to the hypothesis that the deformation process gives a quasi-homogeneous strain state over each cross-section. This was calculated using the following equation:

$r=\int_{-\frac{L_{0}}{2}}^{\frac{L_{0}}{2}} l^{-1}(y) d y / \int_{-\frac{L}{2}}^{\frac{L}{2}} l^{-1}(y) d y$

$L_{0}$ denotes the length of the gauge section, while $L$ represents the global length of the sample. The stored energy rate can then be computed as:

$\tilde{\mathcal{W}}_{s}^{\prime}=\tilde{\mathcal{W}}_{\text {def }}^{\prime}-\tilde{\mathcal{D}}_{1}$

The dark curve in Figs. 8 and 9 corresponds to the mean deformation energy rate per cycle, the green (in web version) curve corresponds to the mean stored energy rate per cycle and the red (in web version) curve indicates the mean intrinsic dissipation per cycle. In order to discuss the energy balance $v s$ ratcheting behavior for the composites under consideration, the variations in mean energies per cycle were plotted as a function of the mean strain. Note that all energy densities were divided by the heat capacity per unit volume $\rho C$ and thus expressed in ${ }^{\circ} \mathrm{C} \mathrm{s}^{-1}$ in order to define, for each energy rate, an equivalent heating rate that is relevant and facilitating comparison of the different energy rates. 

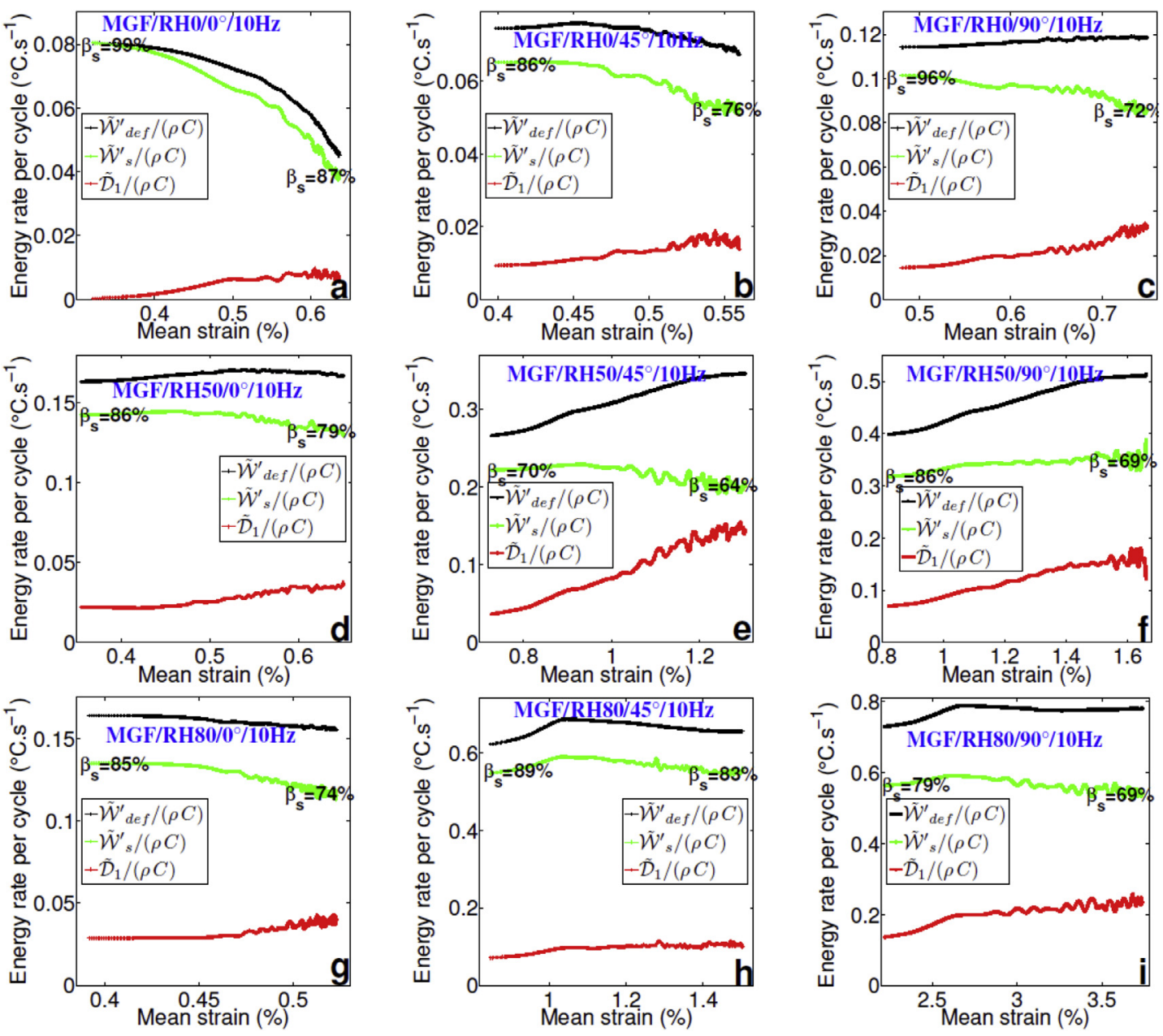

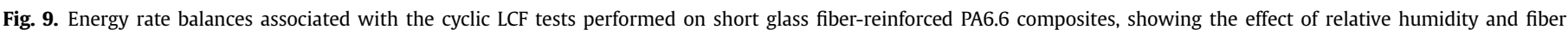
orientation. The load ratio was $R_{\sigma}=0.1$. The geometrical ratio was $r=0.56$ and the volume of the observed gauge area was $v_{g}=82$ mm ${ }^{3}$. The loading frequency was 10 Hz.

According to all the plots, the overall shape of the energy rate balance closely depended on the loading frequency, relative humidity and fiber orientations. For composites at high loading frequency $(=10 \mathrm{~Hz})$, the results indicated a substantial part of the mean stored energy rate per cycle with a ratio accounted 64-87\% (Fig. 9). However, in the case of low loading frequency $(=1 \mathrm{~Hz})$, the trend in the energy rate balance changed completely (Fig. 8). The mean intrinsic dissipation per cycle was, in some cases, predominant compared to the stored energy rate. It started increasing slightly at the beginning of loading and then seemed to stabilize after a certain accumulated strain level (around the first thousands of cycles). Note that this energy stabilization was never accompanied by a stabilized cyclic shakedown. Indeed, except for MGF/RH50/0 $/ 1 \mathrm{~Hz}$ and MGF/ $\mathrm{RH} 80 / 0^{\circ}-45^{\circ} / 1 \mathrm{~Hz}$, where the mean intrinsic dissipation per cycle predominated the mean stored energy rate, the energy rate responses indicated a substantial part of the mean stored energy rate per cycle with ratio exceeding $52 \%$. It is also clear that the stored energy rate proportion at the end of the cycles decreased considerably with increasing relative humidity. Conversely, it seemed to increase with increasing fiber angles. Indeed, it should be noted that this conclusion was true for all the composites prescribed here.

\subsection{Comparative analysis of the energy rate terms}

Based on Fig. 8, the previous energy rate balances were obviously loading frequency, relative humidity and fiber orientation dependent. Another way to observe these effects is to plot and compare the three computed energy rates separately for all investigated composites, as in Fig. 10. The energy data presented in Fig. 10 show the values of the mean deformation energy rate per cycle (Fig. 10, plot a), the mean intrinsic dissipation per cycle (Fig. 10, plot b) and the mean stored energy rate per cycle (Fig. 10, plot c), all obtained at a $1 \mathrm{~Hz}$ loading frequency.

First, all curves clearly did not start at the same mean strain level. This was due to the application of the initial monotone loading of the specimen to reach the minimum cyclic loading stress value (see. Fig. 10, plot a, stage A). Note also that MGF/RH80/90/ $1 \mathrm{~Hz}$ and $\mathrm{MGF} / \mathrm{RH} 50 / 90^{\circ} / 1 \mathrm{~Hz}$ displayed high cyclic ratcheting with high values for all computed energy rates. Besides, the set of dry and/or longitudinal fiber composites (curves surrounded by the brown (in web version) circle) were gathered in the region of low energy rates, with mean intrinsic dissipation and stored energy rate values not exceeding $0.02{ }^{\circ} \mathrm{C} \mathrm{s}^{-1}$ and $0.04{ }^{\circ} \mathrm{C} \mathrm{s}^{-1}$, respectively.

Now regarding the time courses of each type of energy rate, we observed:

- Low fluctuations in the mean deformation energy rate per cycle and steep increases of the mean intrinsic dissipation. In addition, it can be seen that as the relative humidity and fiber angles increased, the mean energy rate values also increased.

- Noticeable decreases in stored energy rates per cycle for all composite materials. In addition, these stored energy rates remained positive and never stabilized, thus indicating internal 

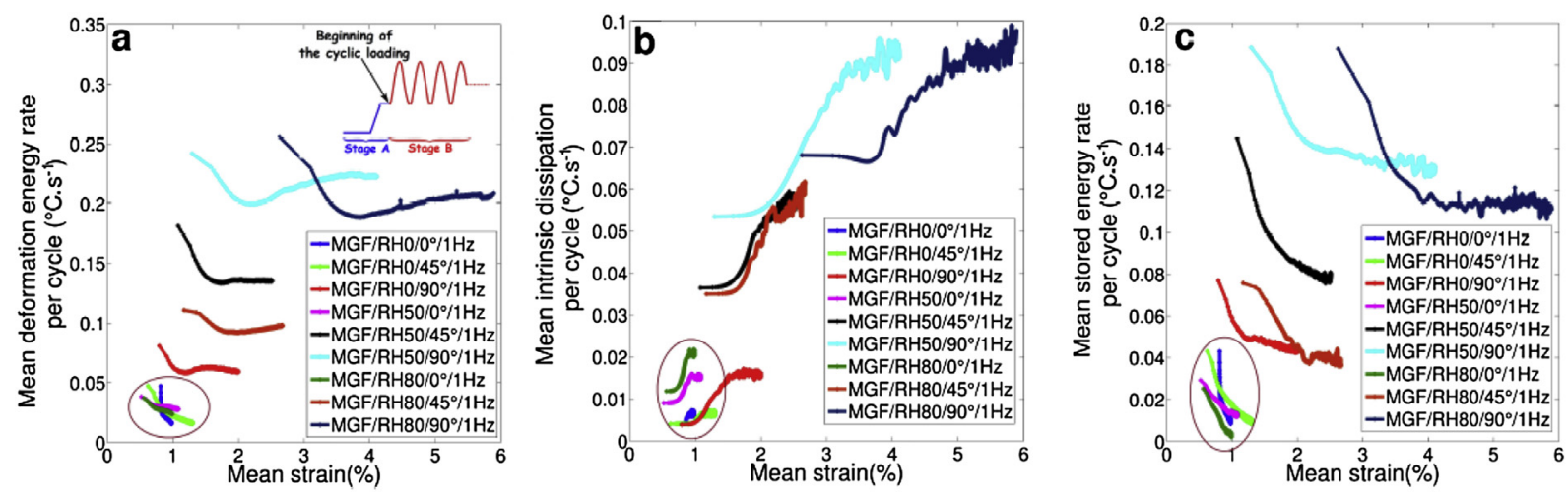

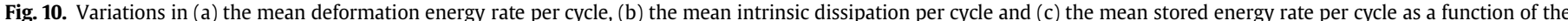
mean strain for all the hygrometric composite specimens subjected to a loading frequency of $1 \mathrm{~Hz}$ and a load ratio of $R_{\sigma}=0.1$.
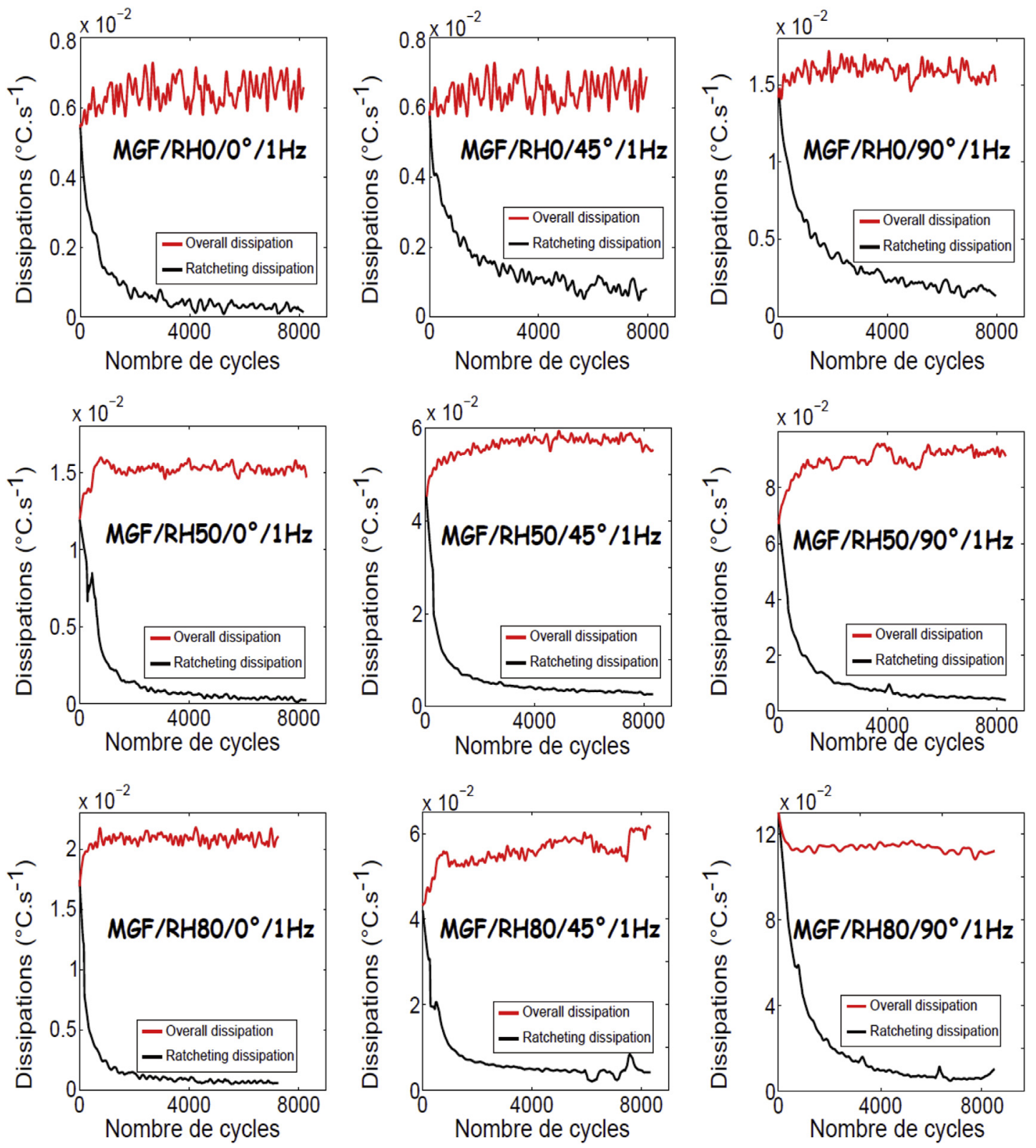

Fig. 11. The ratcheting energy rate and the overall dissipation as functions of the number of cycles for the various studied composites. 
energy variations associated with each loading cycle. Finally, as revealed in Fig. 10 (c), the stored energy rates were also strongly dependent on the relative humidity as well as on the fiber angles.

\subsection{Dissipative analysis of deformation mechanisms}

The mechanical cyclic response of the composite specimens can be schematically split into the oscillatory response and the monotone creep response induced by the mean stress. It could thus be interesting to estimate the dissipation associated with each deformation mechanism. The thermal data enabled us to estimate the overall dissipation (i.e. the intrinsic dissipation defined in Eq. (3), spatially averaged over the volume element under investigation and over a loading time period). We propose hereafter to assess the "dissipative" contribution of the ratcheting effect. This "ratcheting" energy rate per unit volume $\mathcal{D}_{\text {Rat }}$ can be defined by:

$\mathcal{D}_{\text {Rat }}=\sigma_{\text {ave }} \cdot \dot{\varepsilon}_{\text {ave }}$

where $\sigma_{a v e}$ and $\dot{\varepsilon}_{a v e}$ are the mean stress and the mean strain rate, respectively.

Fig. 11 shows the experimental results of the overall dissipation and the ratcheting energy rate as a function of the number of cycles for the composite specimens under investigation. First, the ratcheting energy rate clearly decreased with the increase in the number of cycles. The ratcheting energy rate curves can be divided into two stages. In the first stage, the ratcheting energy rate was initially high and quasi-equal to the overall dissipation, but it rapidly decreased to a nearly asymptotic and positive value. This decrease lasted only around 1500 to 2000 cycles for humid composites and 4000 cycles for dry-as-molded composites. During the second stage, the ratcheting energy rate remained nearly constant, and this stage lasted throughout much of the fatigue test.

All of these findings clearly showed that, at the beginning of the cyclic loading, the ratcheting effect was prominent and this predominance decreased progressively to leave place to dissipative cyclic effects. For instance, we observed ratcheting energy rate of about $64-75 \%$ at cycle number 75 and $0.5-2 \%$ at the end of the cyclic loading.

\section{Concluding comments}

A series of experimental investigations were carried out on short glass fiber-reinforced PA6.6 composites to evaluate and characterize their LCF thermomechanical behavior. Different hygrometric states, loading frequencies and fiber configurations were considered. Several parameters, such as the hysteresis area, mean slope and mean strain per cycle were computed in order to present the LCF cyclic pattern of the material mechanical hysteresis loops. Thermal responses were also examined to quantify the order of magnitude of the specimen self-heating. Based on the analysis of the test findings, the most noticeable and useful features obtained from the experiments are summarized as follows:

- Regarding the hysteresis areas, the loops associated with the fiber composites oriented at $0^{\circ}$ were much thinner compared to those in composites reinforced with fibers oriented at $45^{\circ}$ and $90^{\circ}$, and their values decreased in almost all cases with an increasing number of cycles.

- With a further increase in the number of cycles, a marked cyclic ratcheting strain increased progressively throughout the cycles, with no clear cyclic stabilization. The ratcheting for fiber-reinforced composites oriented at $45^{\circ}$ and $90^{\circ}$ was much higher than that for $0^{\circ}$ composites. This ratcheting phenomenon was also sensitive to the relative humidity change and loading frequency. The mean strain values were much higher for high relative humidity and low loading frequency. This behavior was logically similar to that observed in the PA6.6 matrix.

- The decrease in the mean slope up to 8500 cycles was divided into two major stages. The first one was characterized by a steep decrease during the first few cycles, whereas the second stage was characterized by a lower decrease. The results implied that increasing relative humidity and fiber angles (where the fibers changed from longitudinal to transverse directions) led to a decrease in the mean slope.

- With the further increase in the number of cycles, the results obtained from the thermal responses showed that the maximum self-heating reached by the composite materials was obviously loading frequency, relative humidity and fiber orientation dependent. The maximum self-heating increased when the fiber angles changed from the longitudinal fiber composite to the $45^{\circ}$ and $90^{\circ}$ fiber composites. The same observation was deduced when the relative humidity and loading frequency increased.

- The overall shape of the energy rate balance also closely depended on the loading frequency, relative humidity and fiber orientations. The stored energy rate proportion at the end of cycles decreased considerably with increasing relative humidity and loading frequency. Conversely, the trends of this stored proportion seemed to increase with increasing fiber angles.

- The results obtained from the comparison of energy ranges indicated that as the relative humidity and fiber angles increased the mean of the energy rate values increased concomitantly.

- The assessments of the overall dissipation (derived from thermal data) and of the ratcheting energy rate (derived from stress and strain measurements) confirmed the prominent character of the creep effects at the beginning of the low cycle fatigue test.

\section{Acknowledgments}

The authors gratefully acknowledge Solvay Engineering Plastics for supporting this work and for providing material data and specimens. This work benefited from the financial support of the French Minister for Research (ANRT) (Grant no: CNRS 079212: UM2 121532) and was performed in the framework of the European DURAFIP project (FUI project supported by Oseo).

\section{References}

[1] Launay A, Marco Y, Maitournam MH, Raoult I. Modelling the influence of temperature and relative humidity on the time-dependent mechanical behaviour of a short glass fibre reinforced polyamide. Mech Mater 2013;56: $1-10$.

[2] Erhard G. Designing with plastics. Hanser Gardner Publications; 2006.

[3] Monson L, Braunwarth M, Extrand CW. Moisture absorption by various polyamides and their associated dimensional changes. Appl Polym Sci 2008;107:355-63.

[4] Launay A, Maitournam MH, Marco Y, Raoult I, Szmytka F. Cyclic behaviour of short glass fibre reinforced polyamide: experimental study and constitutive equations. Int J Plasticity 2011;27:1267-93.

[5] Arif MF, Saintier N, Meraghni F, Fitoussi J, Chemisky Y, Robert G. Multiscale fatigue damage characterization in short glass fiber reinforced polyamide- 66 . Compos Part B: Eng 2014;61:55-65.

[6] Benaarbia A, Chrysochoos A, Robert G. Influence of relative humidity and loading frequency on the PA6.6 cyclic thermomechanical behavior: Part I. Mechanical and thermal aspects. Polym Test 2014;40:290-8.

[7] Sperling LH. Introduction to physical polymer science. 2nd ed. New York: JWiley \& Sons., Inc.; 1992.

[8] Rodriguez F. Principles of polymer systems. Recycling and resource recovery. 4th ed. Washington, DC: Taylor \& Francis; 1996 [Chapter 13]. 
[9] Bliznyuk VN, Assender FE, Briggs GAD. Surface glass transition temperature of amorphous polymers. A new insight with SFM. Macromolecules 2002;35: $6613-22$.

[10] Benarbia A, Chrysochoos A, Robert G. Kinetics of stored and dissipated energies associated with cyclic loadings of dry polyamide 6.6 specimens. Polym Test 2014:34:155-67.

[11] Benaarbia A, Chrysochoos A, Robert G. Fiber orientation effects on heat source distribution in reinforced polyamide 6.6 subjected to low cycle fatigue. J Eng Math 2014;90:13-36. http://dx.doi.org/10.1007/s10665-014-9720-7.

[12] Arif MF, Meraghni F, Chemisky Y, Despringre N, Robert G. In situ damage mechanisms investigation of PA66/GF30 composite: effect of relative humidity. Compos Part B: Eng 2014;58:487-95.

[13] Bergeret A, Ferry L, Ienny P. Influence of the fibre/matrix interface on ageing mechanisms of glass fibre reinforced thermoplastic composites (PA6,6, PET, PBT) in a hygrothermal environment. Polym Degrad Stab 2009;94: $1315-24$.

[14] Bernasconi A, Kulin RM. Effect of frequency upon fatigue strength of a short glass fiber reinforced polyamide 6: a superposition method based on cyclic creep parameters. Polym Compos 2009;30:154-61.

[15] Horst JJ, Spoormaker JL. Mechanisms of fatigue in short glass fiber reinforced polyamide 6. Polym Eng Sci 1996;36:2718-26.

[16] Seignobos E. Compréhension des mécanismes physiques de fatigue dans le polyamide vierge et renforcé de fibres de verre. PhD thesis. New York: INSA Lyon; 2009.

[17] Farren WS, Taylor GI. The heat developed during plastic extension of metals. Proc R Soc A: Math Phys Eng Sci 1925;107:422-51.

[18] Taylor GI, Quinney $H$. The latent energy remaining in a metal after cold working. Proc R Soc A: Math Phys Eng Sci 1934;143:307-26.

[19] Williams RO. In: Herman H, editor. Experimental methods of materials research. Interscience; 1967.

[20] Leach JSLL. In: Rapp RA, editor. Physicochemical measurements in metals research. Interscience; 1970.

[21] Chrysochoos A. Energy balance for elastic plastic deformation at finite strain (in French). J de Mécanique Théorique Appliquée 1985:5:589-614.

[22] Chrysochoos A, Maisonneuve O, Martin G, Caumon H, Chezeaux JC. Plastic and dissipated work and stored energy. Nucl Eng Des 1989;114:323-33.

[23] Oliferuk W. Maj M, Raniecki B. Experimental analysis of energy storage rate components during tensile deformation of polycrystals. Mater Sci Eng A Struct Mater Prop Microstruct Process 2004;374:77-81.
[24] Macdougall D. Determination of the plastic work converted to heat using radiometry. Exp Mech 2000;40:298-306.

[25] Hodowany J, Ravichandran G, Rosakis AJ, Rosakis P. Partition of plastic work into heat and stored energy in metals. Exp Mech 2000;40:113-23.

[26] Chrysochoos A, Wattrisse B, Muracciole JM, El Kaim Y. Fields of stored energy associated with localized necking of steel. J Mech Mater Struct 2009;4: 245-62.

[27] Dumoulin S, Louche H, Hopperstad O, Borvik T. Heat sources, energy storage and dissipation in high-strength steels: experiments and modelling. Eur ] Mech A/Solids 2010;29:461-74.

[28] Bouffera R, Pron H, Henry JF, Bissieux C, Beaudoin JL. Study of the intrinsic dissipation associated to the plastic work induced by a ball impact. Int J Therm Sci 2005;44:115-9.

[29] Oliferuk W, Pgadaj S, Grabski M. Energy storage during the tensile deformation of armco iron and austenitic steel. Mater Sci Eng 1985;70:131-41.

[30] Rosakis P, Rosakis AJ, Ravichandran G, Hodowany J. A thermodynamic interna variable model for the partition of plasticwork into heat and stored energy in metals. J Mech Phys Solids 2000;48:581-607.

[31] Louche H, Tabourot L. Experimental energetic balance associated to the deformation of an aluminum multicrystal and monocrystal sheet. Mater Sci Forum 2004;467:1395-400.

[32] Oliferuk W, Maj M. Stress-strain curve and stored energy during uniaxia deformation of polycrystals, Eur J Mech A/Solids 2009:28:266-72.

[33] Arif MF. Damage mechanisms in short glass fiber reinforced polyamide-66 under monotonic and fatigue loading : effect of relative humidity and injection molding induced microstructure. Phd thesis. Arts et Métiers ParisTech Metz; 2014.

[34] Honorat V, Moreau S, Muracciole JM, Wattrisse B, Chrysochoos A. Calorimetric analysis of polymer behaviour using a pixel calibration of an IRFPA camera. Qirt J 2005;2:153-71.

[35] Boulanger T, Chrysochoos A, Mabru C, Galtier A. Calorimetric analysis of dissipative and thermoelastic effects associated with the fatigue behavior of steels. Int J Fatigue 2004;26:221-9.

[36] Chrysochoos A, Huon V, Jourdan F, Muracciole JM, Peyroux R, Wattrisse B. Use of full-field digital image correlation and infrared thermography measurements for the thermomechanical analysis of material behaviour. Strain 2001;46:117-30.

[37] Chrysochoos A, Louche $\mathrm{H}$. An infrared image processing to analyse the calorific effects accompanying strain localization. Int J Eng Sci 2000;38:1759-88. 